\title{
Class A and D Extended-Spectrum $\beta$-Lactamases in Imipenem Resistant Pseudomonas aeruginosa Isolated From Burn Patients in Iran
}

\author{
Sanaz Pakbaten Toupkanlou ${ }^{1}$; Shahin Najar Peerayeh ${ }^{1, *} ;$ Rahim Pirhajati Mahabadi $^{1}$ \\ ${ }^{1}$ Department of Bacteriology, Faculty of Medical Sciences, Tarbiat Modares University, Tehran, IR Iran \\ ${ }^{*}$ Corresponding author: Shahin Najar Peerayeh, Department of Bacteriology, Faculty of Medical Sciences, Tarbiat Modares University, Tehran, IR Iran. Tel: +98-2182884555, Fax: \\ +98-2182884555, E-mail: najarp_s@modares.ac.ir
}

Received: February 20, 2014; Revised: August 3, 2014; Accepted: September 20, 2014

\begin{abstract}
Background: Pseudomonas aeruginosa remains a leading cause of severe wound infection and mortality in burn patients.
Objectives: The current study aimed to determine the prevalence of Ambler class A and D $\beta$-lactamases among P. aeruginosa isolated from infected burn injuries in Tehran, Iran.

Patients and Methods: Bacteriological samples were taken from burn patients with clinical symptoms of burn infection. Fifty Gramnegative, oxidase-positive, catalase- positive bacilli, grown at $42^{\circ} \mathrm{C}$ and production of pigment on Mueller-Hinton agar were identified as P. aeruginosa. All of the 50 isolates were examined for antibiotic susceptibility via disk diffusion method, and production of Ambler class $A$ and and D $\beta$-lactamases by phenotypic screening test. The presence of Ambler class A and D $\beta$-lactamases was confirmed by polymerase chain reaction technique.

Results: The results showed that the majority of isolates (88\%) were multi-drug resistant. Out of these 50 imipenem resistant isolates, 7

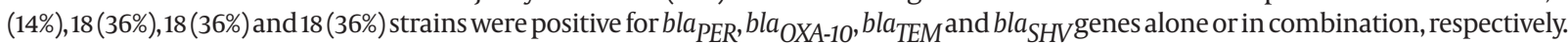
None of the isolates possessed bla $_{\mathrm{KPC}}$ or bla $_{\mathrm{GES}}$ genes.

Conclusions: The current study highlights that the high level of resistance to many antibacterial agents and a gradual increase in the degree of PER, OXA-10, SHV and TEM ESBLs among the majority of imipenem resistant $P$. aeruginosa isolated from patients with burn infection is an enormous threat in burn centers in Iran.
\end{abstract}

Keywords: Imipenem; bla ${ }_{P E R}$, bla ${ }_{\text {OXA-10 }}$, bla $_{T E M}$, bla $_{S H V}$; Pseudomonas aeruginosa

\section{Background}

The burn wound provides suitable conditions for bacterial growth. Bacterial infection is a serious factor of mortality in burn patients. Incidentally, approximately $75 \%$ of the mortality due to burn wounds is associated with infections (1). An opportunistic, nosocomial pathogen of immunocompromised patients, Pseudomonas aeruginosa, typically infects the burn wounds. A study revealed that $P$. aeruginosa was isolated from $73.9 \%$ of the burn patients in Iran $(2,3)$. In addition, many studies showed that colonization of these bacteria in burn wounds is a main cause of mortality in burn patients in burn treatment centers in Iran (2).

To treat such infections, carbapenems such as imipenem are identified as the most effective agent against $P$. aeruginosa (4). Although imipenem is known as a potential last treatment option for patients with burn lesions, it was revealed that one of the most concerning characteristics of $P$. aeruginosa species is their high resistance to imipenem in hospitalized burn patients in recent years. were reported $16 \%$ - 100\% in Tehran hospitals in various studies (5).

Although metallo- $\beta$-lactamases (MBLs) are one of the most important mechanisms resulting in treatment failure in carbapenem therapy of $P$. aeruginosa infections, these isolates also produce $\beta$-lactamases of class A and D. Class A extended-spectrum $\beta$-lactamases (ESBLs) including TEM, SHV, GES, PER, VEB, CTX-M and IBC families are also found in $P$. aeruginosa strains. extended-spectrum $\beta$-lactamases from the class D, OXA-type enzymes are also detected in P. aeruginosa (6). Also recently, the number of $P$. aeruginosa isolates producing KPC-type carbapenemases raised significantly (7). Plasmid acquired Ambler class A ESBLs such as GES, PER, SHV and TEM types were normally found in Entrobacteriaceae. Class A ESBLs are recently identified in P. aeruginosa but they are reported in a limited areas (8). Compared with the enterobacterial species, in which TEM and SHV ESBLs are found most frequently, OXA and PSE types are the most common $\beta$-lactamases in P. aeruginosa (9).

\section{Objectives}

To the best of the authors knowledge, there is not enough information regarding the prevalence of class A and D ESBLs and the type of involved genes in imipenem

Copyright (C) 2015, Ahvaz Jundishapur University of Medical Sciences. This is an open-access article distributed under the terms of the Creative Commons Attribution-NonCommercial 4.0 International License (http://creativecommons.org/licenses/by-nc/4.0/) which permits copy and redistribute the material just in noncommercial usages, provided the original work is properly cited. 
resistant $P$. aeruginosa in burn patients in Iran. The current study aimed to investigate the prevalence of GES, PER, SHV, TEM and OXA-10 ESBLs as well as KPC carbapenemases among imipenem resistant $P$. aeruginosa strains isolated from the burn patients hospitalized in several burn treatment centers in Tehran, Iran (2).

\section{Patients and Methods}

\subsection{Bacterial Isolates}

Fifty imipenem resistant $P$. aeruginosa species were isolated from hospitalized burn patients from 2009 to 2010 in Tehran, Iran. The isolates were identified as P. aeruginosa by conventional biochemical tests such as oxidase and catalase production, growth at $42^{\circ} \mathrm{C}$, and production of pigment on Mueller-Hinton agar (Merck, Germany). The isolates were stored at $-20^{\circ} \mathrm{C}$ in brain-heart infusion broth (Merck, Germany) with 15\% glycerol for future investigations.

\subsection{Susceptibility Tests and Confirmation of ESBLs Production}

Antimicrobial susceptibility to various antibiotics was carried out using the disc-diffusion method recommend- ed by the clinical and laboratory standards institute (CLSI) guidelines (10). Eleven antibacterial discs including cefotaxime (CTX; $30 \mu \mathrm{g})$, ceftazidime (CAZ; $30 \mu \mathrm{g})$, aztreonam (ATM; $30 \mu \mathrm{g})$, gentamicin $(\mathrm{GM} ; 10 \mu \mathrm{g})$, ciprofloxacin (CIP; $5 \mu \mathrm{g}$ ), amikacin (AN; $30 \mu \mathrm{g}$ ), tobramycin (TOB; $10 \mu \mathrm{g})$, cefepime (CPM; $30 \mu \mathrm{g})$, pipracillin (PIP; $100 \mu \mathrm{g})$, cefixime (CFM; $5 \mu \mathrm{g}$ ), and ticarcillin (TIC; $75 \mu \mathrm{g}$ ) (MAST, UK) were used. ESBLs phenotypic confirmatory tests were performed by combined disc tests, using CTX and CTX/ clavulanic acid $(30 / 10 \mu \mathrm{g})$ and CAZ and CAZ/clavulanic acid $(30 / 10 \mu \mathrm{g})(11)$. The inhibitory zone diameter $\geq 5 \mathrm{~mm}$ was considered positive for ESBLs production.

\subsection{Detection of blaGES, blaPER, blaSHV, blaTEM, blaOXA-10 and blaKPC Genes by Polymerase Chain Reaction}

DNA was extracted by the boiling method (12) and PCR analysis was carried out on all 50 isolates to evaluate the prevalence of the bla $a_{G E S}$, bla $a_{P E R}$, bla $a_{S H V}$, bla $a_{T E M}$, blaOXA-10 ESBLs and bla ${ }_{K P C}$ carbapenemases genes. The DNA amplification program and the specific primers (TAKAPOUZIST, IRAN) used for standard PCR amplification procedures are shown in Table 1 (11,13-17). To detect DNA fragments PCR products were detected by gel electrophoresis in $1.5 \%$ agarose.

\begin{tabular}{|c|c|c|c|c|c|c|c|}
\hline Target & Primer Sequence & $\begin{array}{l}\text { Amplicon } \\
\text { Size, bp }\end{array}$ & $\begin{array}{c}\text { Initial } \\
\text { Denaturation }\end{array}$ & Second Denaturation & $\begin{array}{l}\text { Annealing } \\
\text { Stage, for } 1 \mathrm{~min}\end{array}$ & $\begin{array}{c}\text { First } \\
\text { Extension }\end{array}$ & Last Extension \\
\hline \multirow[t]{3}{*}{ GES } & & & $94^{\circ} \mathrm{C}$ for $4 \mathrm{~min}$ & $\begin{array}{l}35 \text { cycles of denatur- } \\
\text { ation at } 94^{\circ} \mathrm{C} \text { for } 1 \mathrm{~min}\end{array}$ & $60^{\circ} \mathrm{C}$ & $72^{\circ} \mathrm{C}$ for $1 \mathrm{~min}$ & $72^{\circ} \mathrm{C}$ for $10 \mathrm{~min}$ \\
\hline & F(5'-ATGCGCTTCATTCACGCAC-3') & 864 & & & & & \\
\hline & R(5'-CTATTTGTCCGTGCTCAGG -3') & & & & & & \\
\hline \multirow[t]{3}{*}{ PER } & & & $94^{\circ} \mathrm{C}$ for $4 \mathrm{~min}$ & $\begin{array}{l}35 \text { cycles of denatur- } \\
\text { ation at } 94^{\circ} \mathrm{C} \text { for } 1 \mathrm{~min}\end{array}$ & $55^{\circ} \mathrm{C}$ & $72^{\circ} \mathrm{C}$ for $1 \mathrm{~min}$ & $72^{\circ} \mathrm{C}$ for $10 \mathrm{~min}$ \\
\hline & F (5'-ATG AAT GTC ATT ATA AAA GC -3') & 925 & & & & & \\
\hline & R(5'-AAT TTG GGC TTA GGG CAG AA-3') & & & & & & \\
\hline \multirow[t]{3}{*}{ SHV } & & & $94^{\circ} \mathrm{C}$ for $4 \mathrm{~min}$ & $\begin{array}{l}35 \text { cycles of denatur- } \\
\text { ation at } 94^{\circ} \mathrm{C} \text { for } 1 \mathrm{~min}\end{array}$ & $58^{\circ} \mathrm{C}$ & $72^{\circ} \mathrm{C}$ for $1 \mathrm{~min}$ & $72^{\circ} \mathrm{C}$ for $10 \mathrm{~min}$ \\
\hline & F(5'-AAGATCCACTATCGCCAGCAG-3') & 231 & & & & & \\
\hline & R(5'-ATTCAGTTCCGTTTCCCAGCGG-3') & & & & & & \\
\hline \multirow[t]{3}{*}{ TEM } & & & $94^{\circ} \mathrm{C}$ for $4 \mathrm{~min}$ & $\begin{array}{l}35 \text { cycles of denatur- } \\
\text { ation at } 94^{\circ} \mathrm{C} \text { for } 1 \mathrm{~min}\end{array}$ & $55^{\circ} \mathrm{C}$ & $72^{\circ} \mathrm{C}$ for $1 \mathrm{~min}$ & $72^{\circ} \mathrm{C}$ for $10 \mathrm{~min}$ \\
\hline & F(5'-ATGAGT ATTCAACATTTCCG-3') & 858 & & & & & \\
\hline & R(5'-CCAATGCTTAATCAGTGAGG-3') & & & & & & \\
\hline \multirow[t]{3}{*}{ OXA-10 } & & & $94^{\circ} \mathrm{C}$ for $4 \mathrm{~min}$ & & $58^{\circ} \mathrm{C}$ & $72^{\circ} \mathrm{C}$ for $1 \mathrm{~min}$ & $72^{\circ} \mathrm{C}$ for $10 \mathrm{~min}$ \\
\hline & F (5'-TCAACAAATCGCCAGAGAAG-3') & 276 & & & & & \\
\hline & R(5'-TCCCACACCAGAAAAACCAG-3') & & & & & & \\
\hline \multirow[t]{3}{*}{ KPC } & & & $94^{\circ} \mathrm{C}$ for $4 \mathrm{~min}$ & $\begin{array}{l}35 \text { cycles of denatur- } \\
\text { ation at } 94^{\circ} \mathrm{C} \text { for } 1 \mathrm{~min}\end{array}$ & $52^{\circ} \mathrm{C}$ & $72^{\circ} \mathrm{C}$ for $1 \mathrm{~min}$ & $72^{\circ} \mathrm{C}$ for $10 \mathrm{~min}$ \\
\hline & F(5'-ATGTCACTGTATCGCCGTCT-3') & 893 & & & & & \\
\hline & R(5'-TTTTCAGAGCCTTACTGCCC-3’) & & & & & & \\
\hline
\end{tabular}




\section{Results}

The results of antibiogram testing showed that all isolates (100\%) were resistant to CTX, CPM, PIP, CFM and TIC. Meanwhile, the findings revealed that 49 (98\%) isolates were resistant to CAZ, CIP and 48 (96\%) isolates were resistant to ATM, AN, GM and TOB. Most of the isolates were resistant to various classes of antibacterial agents (Table 2). Among the 50 isolates, 44 (88\%) were multi-drug resistant and phenotypic tests indicated that 27 (54\%) strains were presumed ESBLs producers. Among the 27 strains, 23 (85.18\%) were determined with zone diameters of 5 $14 \mathrm{~mm}$ in combination with CAZ/clavulanic acid and 17 (62.96\%) were determined with zone diameters of $5-12$ $\mathrm{mm}$ in combination with CTX/clavulanic acid.

PCRanalysis was carried out for all 50 isolates using primers specific to bla $a_{P E R}, b_{G E S}, b l a_{O X A-10}, b_{T E M}, b_{S H V}$ and bla $_{K P C}$. Four of six genes were detected alone or in various combinations; 7 (14\%), 18 (36\%), 18 (36\%), 18 (36\%) strains of a total of 50 isolates were amplified as bla PER $_{\text {, bla }}$ OXA-10, bla$T E M$ and bla $_{S H V}$, respectively(Figure 1). Whilst among the 27 isolates indicated as presumed ESBLs producers phenotypically, 3 (11.11\%), 12 (42.85\%), 14 (50\%) and 14 (50\%) strains were detected as bla $a_{P E R}$, blaOXA-10, bla $a_{T E M}$ and bla $a_{S H V}$ genes, respectively. In addition, among isolates, 10 (20\%) carried blaTEM, bla $_{\text {OXA-10 }}$ and bla ${ }_{S H V}$ genes, simultaneously. Also 98\% of SHV, TEM and OXA-10 producing strains were resistant to all of the antibiotics used in this research. No bla $K P C$ and bla ${ }_{G E S}$ genes were detected in the study. Table 3 shows that approximately all of the isolates harboring multiple antimicrobial resistance genes were $100 \%$ resistant to different classes of antibiotics except CIP.

Table 2. Relationship Between Antibacterial Pattern and Imipenem Resistant Isolates Carrying ESBLs Genes Alone ${ }^{\mathrm{a}}$

\begin{tabular}{lcccc}
\hline \multirow{2}{*}{ Antibiotics } & \multicolumn{3}{c}{ Antibiotic Resistant Isolates Carrying ESBLs Genes Alone } \\
\cline { 2 - 5 } & PER: $\mathbf{1 4} \%$ & SHV:36\% & TEM: 36\% & OXA-10:36\% \\
\hline CTX & 100 & 100 & 100 & 100 \\
\hline CAZ & 100 & 100 & 100 & 100 \\
ATM & 100 & 100 & 100 & 100 \\
GM & 98 & 100 & 100 & 100 \\
CIP & 100 & 98 & 98 & 100 \\
AN & 98 & 100 & 100 & 100 \\
TOB & 98 & 100 & 100 & 100 \\
CPM & 100 & 100 & 100 & 100 \\
PIP & 100 & 100 & 100 & 100 \\
CFM & 100 & 100 & 100 & 100 \\
TIC & 100 & 100 & 100 & \\
\hline
\end{tabular}

a Abbreviations: AN, amikacin; ATM, aztreonam; CAZ, ceftazidime; CFM, cefixime; CIP, ciprofloxacin; CPM, cefepime; CTX, cefotaxime; GM, gentamicin; PIP, pipracillin; R, resistant; TIC, ticarcillin; TOB, tobramycin.

Figure 1. Electrophoresis of PCR Products for Amplifying bla ${ }_{G E S}$, bla $_{P E R}$,

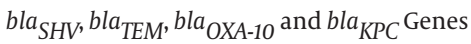

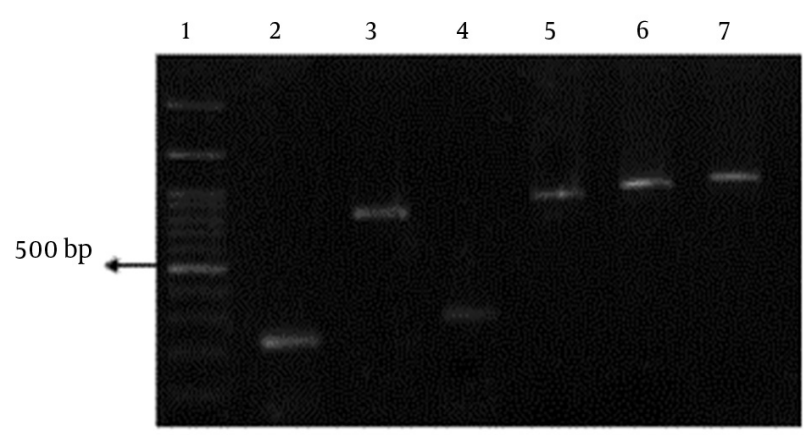

No 1, DNA marker (100 kb). No 2, bla ${ }_{S H V}(231 \mathrm{bp})$, No 3, bla ${ }_{T E M}$ (858 bp), No 4, bla ${ }_{O X A-10}$ (276), No 5, positive control for bla ${ }_{G E S}$ (864 bp), No 6, positive control for bla $\mathrm{KPC}$ (893 bp), No 7, bla ${ }_{\text {PER }}$ (925 bp).
Table 3. Relationship Between Antibacterial Pattern and Imipenem Resistant Isolates Carrying ESBLs Genes in Various Combinations $^{\mathrm{a}}$

\begin{tabular}{lcc}
\hline Antibiotics & \multicolumn{2}{c}{$\begin{array}{c}\text { Resistant Isolates Carrying ESBL } \\
\text { Genes }\end{array}$} \\
\cline { 2 - 3 } & TEM + SHV & PER+ OXA \\
\hline CTX & 100 & 100 \\
\hline CAZ & 100 & 100 \\
\hline ATM & 100 & 100 \\
\hline GM & 100 & 100 \\
CIP & 6.25 & 100 \\
\hline AN & 100 & 100 \\
TOB & 100 & 100 \\
\hline CPM & 100 & 100 \\
PIP & 100 & 100 \\
\hline CFM & 100 & 100 \\
TIC & 100 & 100 \\
\hline P & 100 & \\
\hline
\end{tabular}

a Abbreviations: AN, amikacin; ATM, aztreonam; CAZ, ceftazidime; CIP, ciprofloxacin; CFM, cefixime; CPM, cefepime; CTX, cefotaxime; GM, gentamicin; TOB, tobramycin; PIP, pipracillin; TIC, ticarcillin. 


\section{Discussion}

The application of antibiotics is one of the most important scientific attainments of the 20th century. However, prevalent antibiotic use increases antibiotic-resistant pathogens, including multidrug resistant isolates (18). Antibiotic resistance of pathogenic bacteria is a major global danger and Realization of the resistance mechanisms is critical to development of novel therapeutic options (18). Pseudomonas aeruginosa is the predominant bacterial pathogen in patients with burn injuries. The resistance of this microorganism to antibiotics is a worrisome problem in hospitalized patients with burn injuries. Extended spectrum $\beta$-lactamases, carbapenemases, metallo $\beta$-lactamases and AmpC $\beta$-lactamases producing organisms are the main problems to treat the infected burn patients in burn centers (1). One of the most important ways to select an effective method to reduce such infections is specifying the relationship between genotype and drug susceptibility (1). Multidrug-resistant $P$. aeruginosa isolates re a worrying matter from burn patients in Iran (19). Several classes of ESBLs such as OXA, PER, TEM, SHV and GES are newly detected in P. aeruginosa. Also recently, the number of $P$. aeruginosa isolates producing KPC-type carbapenemases has significantly raised (7).

The findings of the present study explained that high levels of resistance to many antimicrobial antibiotics existed among $P$. aeruginosa isolated from the infected wounds of burn patients and the majority of isolates (88\%) were multi-drug resistant. All isolates were totally resistant to CTX, CPM, PIP, CFM and TIC; whereas the minimum resistance rate (96\%) was demonstrated for ATM, GM, TOB and AN. Results of the previous studies approved resistance to a large number of antibiotics usually used to treat burn injuries caused by P. aeruginosa in the Iranian hospitals (19). For instance, Shahcheraghi et al. reported that nosocomial $P$. aeruginosa isolates were resistant to cefotaxime (56\%) and ceftazidime (25\%) (20). In another study, the rates of resistance were as follows: ceftazidime (74.8\%) and cefotaxime (50.4\%) (19). Moreover, among 27 isolates, phenotypically positive for ESBLs production, 0 (0\%), 12 (42.85\%), 14 (50\%) and 14 (50\%) strains were detected as bla ${ }_{P E R}, b l a_{O X A-10}, b_{\text {TEM }}$ and bla $a_{S H V}$ genes, respectively. Shahcheraghi et al. reported that the frequency of bla $_{P E R}$, bla $a_{T E M}$, bla $_{S H V}$ and bla $a_{\text {GES }}$ were $17 \%, 9 \%, 22 \%$ and $0 \%$, respectively (20).

To find more information about the prevalence and type of the relevant genes involved in the multi-drug resistance of nosocomial P. aeruginosa isolates, the PCR experiments were performed for all 50 isolates. Of the 50 isolates, 7 (14\%), 18 (36\%), 18 (36\%) and18 (36\%) strains were positive for bla $a_{P E R}, b l a_{O X A-10}, b l a_{T E M}$ and $b l a_{S H V}$ alone or in various combinations, respectively. In addition, earlier reports from Iran also showed that the prevalence of blaPER-1 and bla OXA-10 were $49.25 \%$ and $74.62 \%$, respectively (2). The observations suggest that the prevalence of bla-

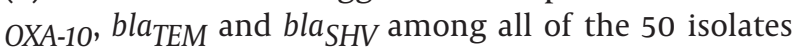

were relatively high in the present work. Except in Turkey, in which PER (86\%) and OXA-10 (55\%) as well as Saudi Arabia in which OXA-10 (56\%) and GES (20\%) producing $P$. aeruginosa strains were reported $(21,22)$, no current data existed on the real prevalence of these genes in the countries neighboring Iran. It is possible that the distribution of PER and OXA-10 probably associated with the immigration and traveling between Iran and Turkey.

A study conducted in Taiwan showed that TEM, SHV-18 and OXA-10 genes exist in $100 \%, 91.3 \%$ and $21.7 \%$ of the total $P$. aeruginosa strains, respectively (23). Based on the results of PCR assay, there were no bla ${ }_{G E S}$ and bla $K P C$ genes in the 50 tested isolates of $P$. aeruginosa in the current study. There are several case reports on the isolation of KPC-producing P. aeruginosa and Klebsiella species in burned patients in Iran $(24,25)$. There seems to be a gradual increase in KPC-producing P. aeruginosa in the burn centers of Iran. From the clinical point of view, occurrence of KPC-producer Gram-negative bacteria among the burned patients causes a much higher degree of resistance to many antibacterial agents including $\beta$-lactams, quinolones and aminoglycosides (26). These findings increase the concern about the future of antibiotic therapy for KPC-producing P. aeruginosa strains.

In conclusion, the current study described that the high rates of resistance to different antibacterial agents and a gradual increase in the degree of PER, OXA-10, SHV and TEM ESBLs among the majority of imipenem resistant $P$. aeruginosa isolated from the burn patients with infected wounds is an enormous threat in burn centers of Iran. Therefore, molecular epidemiologic studies play a significant role in the evaluation of transmission ways of the pathogen for infection control.

\section{Acknowledgements}

The authors are very grateful to Professor Nordmann for providing the control strain harboring bla ${ }_{G E S}$ and Dr. Shahcheraghi for providing the control strain harboring bla $_{K P C}$ genes.

\section{Authors' Contributions}

All the experimental works and data analysis are done by Sanaz Pakbaten Toupkanlou and Rahim Pirhajati Mahabadi; Dr. Shahin Najar Peerayeh supervised the research.

\section{Funding/Support}

This work was financially supported by grants from faculty of medical sciences, Tarbiat Modares university, Tehran, Iran.

\section{References}

1. Bandekar N, Vinodkumar CS, Basavarajappa KG, Prabhakar PJ, Nagaraj P. Beta lactamases mediated resistance amongst gram negative bacilli in Burn Infection. Biol Med Res. 2003;2(3):766-70.

2. Mirsalehian A, Feizabadi M, Nakhjavani FA, Jabalameli F, Goli 
H, Kalantari N. Detection of VEB-1, OXA-10 and PER-1 genotypes in extended-spectrum beta-lactamase-producing Pseudomonas aeruginosa strains isolated from burn patients. Burns. 2010;36(1):70-4.

3. Rastegar Lari A, Bahrami Honar H, Alaghehbandan R. Pseudomonas infections in Tohid Burn Center, Iran. Burns. 1998;24(7):637-41.

4. Laupland KB, Parkins MD, Church DL, Gregson DB, Louie TJ, Conly JM, et al. Population-based epidemiological study of infections caused by carbapenem-resistant Pseudomonas aeruginosa in the Calgary Health Region: importance of metallo-beta-lactamase (MBL)-producing strains. J Infect Dis. 2005;192(9):1606-12.

5. Moazami-Goudarzi S, Eftekhar F. Assessment of carbapenem susceptibility and multidrug-resistance in Pseudomonas aeruginosa burn isolates in Tehran. JundishapurJ Microbiol. 2013;6(2):162-5.

6. Lister PD, Wolter DJ, Hanson ND. Antibacterial-resistant Pseudomonas aeruginosa: clinical impact and complex regulation of chromosomally encoded resistance mechanisms. Clin Microbiol Rev. 2009;22(4):582-610.

7. Wang XD, Cai JC, Zhou HW, Zhang R, Chen GX. Reduced susceptibility to carbapenems in Klebsiella pneumoniae clinical isolates associated with plasmid-mediated beta-lactamase production and OmpK36 porin deficiency. J Med Microbiol. 2009;58(Pt 9):1196-202.

8. Shakibaei MR, Shahcheraghi F, Hashemi A, Adeli S. Detection of TEM, SHV and PER type extended-spectrum $\beta$-lactamase genes among clinical strains of Pseudomonas aeruginosa isolated burnt patients at Shafa-hospital, Kerman, Iran. Iran J Basic Med Sci. 2008;11(104-11).

9. Weldhagen GF, Poirel L, Nordmann P. Ambler class A extendedspectrum beta-lactamases in Pseudomonas aeruginosa: novel developments and clinical impact. Antimicrob Agents Chemother. 2003;47(8):2385-92.

10. Clinical and Laboratory Standards Institute.. Performance standards for Antimicrobial susceptibility Testing: Document M100-S20.Wayne, PA, USA: CLSI; 2010.

11. Jiang X, Zhang Z, Li M, Zhou D, Ruan F, Lu Y. Detection of extended-spectrum beta-lactamases in clinical isolates of Pseudomonas aeruginosa. Antimicrob Agents Chemother. 2006;50(9):2990-5.

12. Nguyen TV, Le Van P, Le Huy C, Gia KN, Weintraub A. Detection and characterization of diarrheagenic Escherichia coli from young children in Hanoi, Vietnam. J Clin Microbiol. 2005;43(2):755-60.

13. Poirel L, Le Thomas I, Naas T, Karim A, Nordmann P. Biochemical sequence analyses of GES-1, a novel class A extended-spectrum beta-lactamase, and the class 1 integron In52 from Klebsiella pneumoniae. Antimicrob Agents Chemother. 2000;44(3):622-32.
14. Kim J, Lim YM, Rheem I, Lee Y, Lee JC, Seol SY, et al. CTX-M and SHV12 beta-lactamases are the most common extended-spectrum enzymes in clinical isolates of Escherichia coli and Klebsiella pneumoniae collected from 3 university hospitals within Korea. FEMS Microbiol Lett. 2005;245(1):93-8.

15. Leila N, Fereshteh S, Nikbin VS, Shoeib N. PER, CTX-M, TEM and SHV Beta-lactamases in clinical isolates of Klebsiella pneumoniae isolated from Tehran, Iran. Iran J Basic Med Sci. 2010;13(3):111-8.

16. Bhattacharjee A, Sen MR, Anupurba S, Prakash P, Nath G. Detection of OXA-2 group extended-spectrum-beta-lactamase-producing clinical isolates of Escherichia coli from India. J Antimicrob Chemother. 2007;60(3):703-4.

17. Queenan AM, Bush K. Carbapenemases: the versatile beta-lactamases. Clin Microbiol Rev. 2007;20(3):440-58.

18. Kumar A, Schweizer HP. Bacterial resistance to antibiotics: active efflux and reduced uptake. Adv Drug Deliv Rev. 2005;57(10):1486-513.

19. Salimi H, Yakhchali B, Owlia P, Lari AR. Molecular Epidemiology and Drug Susceptibility of Pseudomonas aeruginosa Strains Isolated From Burn Patients. Lab Med. 2010;41(9):540-4.

20. Shahcheraghi F, Nikbin VS, Feizabadi MM. Prevalence of ESBLs genes among multidrug-resistant isolates of Pseudomonas aeruginosa isolated from patients in Tehran. Microb Drug Resist. 2009;15(1):37-9.

21. Tawfik AF, Shibl AM, Aljohi MA, Altammami MA, Al-Agamy MH. Distribution of Ambler class A, B and D beta-lactamases among Pseudomonas aeruginosa isolates. Burns. 2012;38(6):855-60.

22. Aktas Z, Poirel L, Salcioglu M, Ozcan PE, Midilli K, Bal C, et al. PER1- and OXA-10-like beta-lactamases in ceftazidime-resistant Pseudomonas aeruginosa isolates from intensive care unit patients in Istanbul, Turkey. Clin Microbiol Infect. 2005;11(3):193-8.

23. Du SJ, Kuo HC, Cheng CH, Fei ACY, Wei HW, Chang SK. Molecular mechanisms of ceftazidime resistance in Pseudomonas aeruginosa isolates from canine and human infections. Vet Med. 2010;55(4):172-18.

24. Azimi L, Rastegar Lari A, Alaghehbandan R, Alinejad F, Mohammadpoor M, Rahbar M. KPC-producer gram negative bacteria among burned infants in Motahari Hospital, Tehran: first report from Iran. Ann Burns Fire Disasters. 2012;25(2):74-7.

25. Rastegar Lari A, Azimi L, Rahbar M, Fallah F, Alaghehbandan R. Phenotypic detection of Klebsiella pneumoniae carbapenemase among burns patients: first report from Iran. Burns. 2013;39(1):174-6.

26. Gupta N, Limbago BM, Patel JB, Kallen AJ. Carbapenem-resistant Enterobacteriaceae: epidemiology and prevention. Clin Infect Dis. 2011;53(1):60-7. 